\title{
Editorial
}

\section{Key approaches to nosocomial infection control}

Antibiotic resistance has become a global problem. Clones of bacteria with multidrug resistance (MDR) to important antibiotics including penicillins, cephamycins, carbapenems, aminoglycosides, and fluoroquinolones are increasing under the pressure of excessive and inappropriate antibiotic use with opportunities for global spread of MDR strains [1, 2]. The burden of healthcare-associated infections such as pneumonia, surgical site infections, gastrointestinal, urinary tract, and primary bloodstream infections have been a serious problem arising in part from inappropriate antibiotic use, complicated by deviceassociated infections (i.e. ventilator-associated pneumonia, catheter-related urinary tract infection, and catheter-related bloodstream infection) [3]. The health care problems associated with infections has posed not only additional morbidity and mortality for patients, but is also associated with significant financial costs [4].

Isolation precautions, environmental cleanliness, and surveillance are standard measures for hospital infection control. Systems of isolation precautions for infection control have been proposed [5]. Standard (universal) precautions recommended for all patients include hand washing before and after every patient contact, cough etiquette, glove, gown, and eye protection as required, and safe disposal of sharp instruments in impervious containers [5]. Contact precautions are needed for health care workers when dealing with patients with bacterial colonization of body sites, enteric infections, scabies, impetigo, and decubitus ulcers. Precautions are also required for patients with suspected possibility of transmission of droplet transmission diseases such as Mycoplasma pneumonia, diphtheria, and Neisseria meningitidis [5]. Healthcare workers for these patients should wear a facemask (use of higher level respirator masks is not required [5]. The doors of rooms used to house these patients may remain open [5]. Precautions against airborne infection of diseases such as Ebola, SARS, and tuberculosis are also essential. These patients should be admitted to an airborne infection isolation room, such as a private room with negative air pressure

Correspondence to: Editorial Office of Asian Biomedicine, Faculty of Medicine, Chulalongkorn University, Bangkok 10330, Thailand.E-mail: chulamed@md.chula.ac.th
[5]. Doors to the isolation rooms must remain closed. Healthcare providers and other persons entering must wear a respirator with a filtering capacity of $95 \%$ that allows a tight seal over the nose and mouth [5]. There are guidelines for sterilization and disinfection processes and products for infection control by device classification [6].

Environmental cleaning is a major component of infection control programs. Environmental cleaning, disinfection, and sterilization are basic and important measures used to avoid hospital acquired infections by reducing contact with medical equipment and contaminated surfaces by healthcare personnel, patients, and their relatives $[7,8]$.

In addition to standard precautions, contact precautions and environmental cleaning, surveillance for nosocomial infection is an important cornerstone of hospital infection control [9, 10]. Avcioglu and Bilkay in this issue proposed yet another method that can be used in surveillance. They suggested that antibiotyping and antibiotype profiles may provide valuable information regarding hospitalized patients that could identify problems areas and allow evidence-based approaches to preventive measures against emergence of new drug resistant nosocomial infection [11]. The utility of the methods warrants further exploration.

\section{References}

1. Hawkey PM, Jones AM. The changing epidemiology of resistance. J Antimicrob Chemother. 2009; 64 (Suppl 1):i3-10.

2. Ramesh N, Prasanth M, Ramkumar S, Suresh M, Tamhankar AJ, Gothandam KM, et al. Colistin susceptibility of gram-negative clinical isolates from Tamil Nadu, India. Asian Biomed. 2016; 10: 35-9.

3. Magill SS, Edwards JR, Fridkin SK. Emerging infections program healthcare-associated infections and antimicrobial use prevalence survey team. Multistate point-prevalence survey of health careassociated infections. N Engl J Med. 2014; 370:2542-3.

4. Marchetti A, Rossiter R. Economic burden of healthcare-associated infection in US acute care hospitals: societal perspective. J Med Econ. 2013; 16: 1399-404.

5. Garner JS. Guideline for isolation precautions in hospitals. Part I. Evolution of isolation practices, Hospital Infection Control Practices Advisory 
Committee. Am J Infect Control. 1996; 24:24-31.

6. Rutala WA. APIC guideline for selection and use of disinfectants. Am J Infect Control. 1996; 24:313-42.

7. Rutala WA, Weber DJ. Surface disinfection: should we do it? J Hosp Infect. 2001; 48(Suppl A):S64-8.

8. Weber DJ, Anderson D, Rutala WA. The role of the surface environment in healthcare-associated infections. Curr Opin Infect Dis. 2013; 26:338-44.

9. Gaynes R, Richards C, Edwards J, Emori TG, Horan T, Alonso-Echanove J, et al. Feeding back surveillance data to prevent hospital-acquired infections. Emerg
Infect Dis. 2001; 7:295-8.

10. Engelhart ST, Hanses-Derendorf L, Exner M, Kramer MH. Prospective surveillance for healthcare-associated infections in German nursing home residents. J Hosp Infect. 2005; 60:46-50.

11. Avcioglu NH, Bilkay IS. Antibiotic resistance, multidrug resistance and enterobacterial repetitive intergenic consensus polymerase chain reaction profiles of clinically important Klebsiella species. Asian Biomed. 2016; 10: 41-7. 